\title{
Establishing Priorities for Sustainable Environmental Design in the Rural Villages of Yunnan, China
}

\author{
Adrian Pitts \\ Department of Architecture and 3D Design, University of Huddersfield, Queensgate, Huddersfield HD1 3DH, \\ UK; a.pitts@hud.ac.uk; Tel.: +44-1484-473288 or +44-1484-472281 \\ Academic Editor: David Arditi
}

Received: 10 July 2016; Accepted: 23 August 2016; Published: 26 August 2016

\begin{abstract}
This paper addresses sustainable rural village development in China. Rural development is unlike the process of urbanization in Chinese cities and reflects different land ownership rules and different organizational structures. Even though there are an increasing number of Chinese residents in cities, there are still more than 600 million people living in the countryside. The attention lavished on city development has been, in part, now refocused to rural villages. Since 2006, the support for large-scale investment in the countryside has created much change; however, not all of this change is well organized, with potential for less than optimum impacts on the environment and sustainability. The paper identifies the key influences and drivers from historic and contemporary points of view. The sustainability of the villages will derive from long-term self-sufficiency, and this must include the understanding of environmental design principles, which enable suitable dwelling design. Two villages are taken as contrasting examples, and information derived from other sources is discussed. Technologies and techniques that can help determine environmental design priorities are evaluated and directions for future development suggested. This includes development of a design support aid with key drivers of: orientation and site location, window design and key construction features.
\end{abstract}

Keywords: buildings; China; design; environmental; rural; sustainability; villages; Yunnan

\section{Introduction}

China has a long history stretching back more than 4000 years; a history rich in culture, the arts, technological development and trade. Over many centuries through a series of dynastic periods, it existed as a large, but mainly rural economy, with less than $10 \%$ of the population located in cities; a situation that persisted up to the middle of the 20th Century. Following the wars against Japan, which became enmeshed with the Second World War and associated internal struggles for power, the establishment of the People's Republic of China in 1949 marked the start of a period of industrialization and urbanization. This was followed by the enactment of a series of five-year plans for development, which have acted both to drive the country to its current status and to define development priorities.

At first in the 1950s and early 1960s, population movement from rural to urban areas was significant (aligned to the period of the "Great Leap Forward"); though it was followed by a period of reversal during the Cultural Revolution (1965-1975), at which time, approximately 18 million young people moved back to the countryside in a phase of "rustication" [1], though most eventually returned to the cities. From 1978, however, as China entered a great period of reform and "opening-up", the movement from rural areas into towns and cities maintained a steady pace, increasing at a rate of about $1 \%$ per year; the present urban population is now estimated at over $55 \%$ of the total. The number of cities (defined by a population of over half a million and a exceeding a certain level of economic activity) rose from 193 in 1978 to 663 in 2012, and this has been associated with a reduction in the number of villages from 3.6 million down to 2.5 million [2]. Nevertheless, more than 600 million 
Chinese still live in rural areas. As a result, any changes in rural development and in the design of villages and their buildings will have a very significant impact, not just on the lives of residents, but also on the economy at large and on resource demand; resource consumption; building design and construction, planning and transport; communication; and on pollution and the local environment. Since rural villages rely on their local environment for livelihoods in a more direct way than cities, it is important to be able to understand how they function and how they can be aided to optimize their future evolution and use of resources. The design, operation, renovation and redevelopment of the buildings within a village are therefore crucial elements to be considered in the analysis, and this has begun to be addressed in the research community [2].

The research described below is a combination of the broad enquiry and understanding of underlying factors and then the evaluation of their impact on contemporary rural sustainability. This is then combined with knowledge gained from on-site case studies and from the consideration of options determined from both the specific and also the more general identification of opportunities to assess and improve environmental design.

\section{Yunnan and Southwest China}

The focus area for the larger research study of which this paper reports a part is southwest China, the provinces of Yunnan, Guizhou and Sichuan. Also associated is the city of Chongqing and its environs (which is currently one of China's four centrally-controlled municipalities, but which was formerly part of Sichuan). The outline of the location is shown in Figure 1.

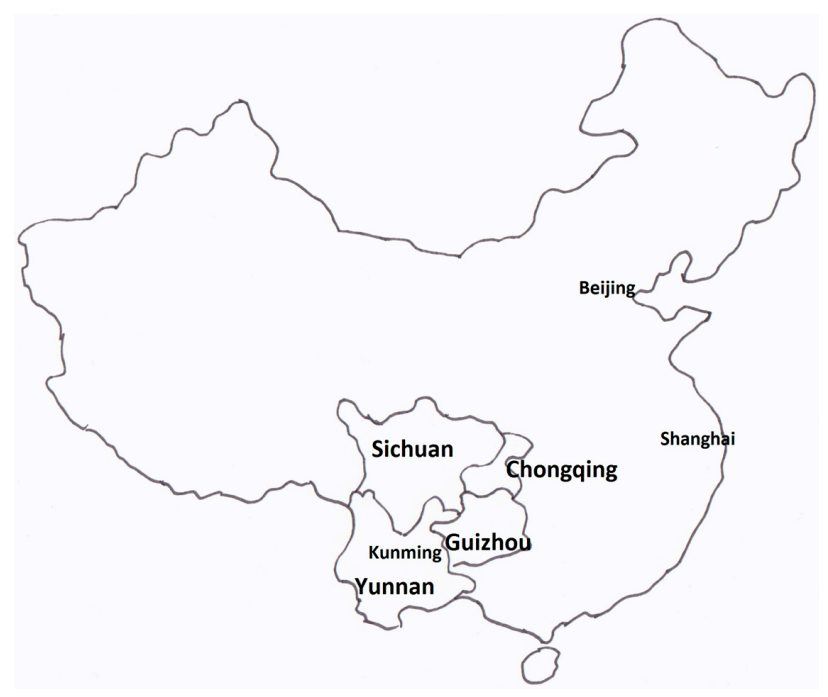

Figure 1. Map of China showing the provinces of interest, including Yunnan.

These provinces were historically somewhat isolated from the large and influential coastal metropolises of the east; indeed, Yunnan was at one time considered a place of internal exile within the Chinese state (for example, during the Qing Dynastic period); somewhere cut-off because of distance and terrain. The area has also found itself subject to a range of natural disasters being prone to earthquakes and also periods of extreme weather. The level of isolation has reduced remarkably in recent decades with the increased availability of air travel and with the opening of the Shanghai to Kunming railway in 2016, cutting train journey times from about 20 to only $8 \mathrm{~h}$ [3].

Southwest China does differ in a number of ways from its eastern counterparts: the ethnic nationality mix is particularly strong with 25 of the 55 minority groups being represented within Yunnan and comprising $38 \%$ of the total population. In Guizhou, the ethnic population is even more diverse and represents $56 \%$ of residents; the ethnic proportion is, though, rather lower in Sichuan. The prevalence of the ethnic nationalities does bring a different vitality and alternatives for 
development in rural areas where villages are often predominantly occupied by members of just one ethnic group. Ethnic groups also have their many own traditions for building [4], and this can be seen as a physical manifestation to be experienced in the Yunnan Nationalities Village in Kunming. The variations in style, materials and construction methods provide a vivid indication of the different internal conditions that can be experienced by occupants.

This area is also close to the borders with other states: Myanmar, Thailand, Laos and Vietnam; the cross-border influences, very prevalent in the past, are still to be felt in the modern day. The first railway link was established between Vietnam and Yunnan with French support over 100 years ago (the Kunming to Hai Phong railway built between 1904 and 1910), and much trade continues with countries to the south. The new fast rail link to Shanghai is also expected to open up Kunming and Yunnan to act as a focal point for the Greater Mekong sub-region economic area. As a result, some have suggested a revival for the former southern Silk Road route linking Kunming to Kolkata in India, through Myanmar and Bangladesh [5].

The remoteness of southwest China in the past together with difficult terrain (the main river valleys run north to south hindering transport from east to west) perhaps limited economic development and frustrated trade with the east. The differences are becoming less distinct, however, and the tourist potential of some of the area is being recognized and developed. Yunnan and its recent development have also been a fruitful location for researching architecture in connection with ethnic and cultural issues [6].

Almost a decade ago, a wide-ranging study of the sustainability of Chinese villages was carried out by a multi-national and multi-disciplinary team led from Austria (the SUCCESS project) [7]. Almost all of the villages studied in that project were from the central eastern zone of China, though two were located in Yunnan. The project described in this paper is therefore a timely opportunity to revisit some of the outcomes and issues that are arising.

A significant factor, affecting the environmental performance of buildings, is the climate. This has an impact on material choices and modes of construction, as well as on performance in use and maintenance requirements. Across the three provinces initially chosen for the broader study, there are significant variations in climate. The city of Chongqing is often referred to as one of the three "furnaces" of the Yangtze River Valley (and of China more generally) due to its excessive heat in summer months. By comparison, Kunming, the provincial capital of Yunnan, is referred to as the "city of eternal spring" because of its more moderate climate conditions. Yunnan's situation benefits from its altitude; although the province is situated close to the Tropic of Cancer, its elevation above sea-level, which is typically of the order of $2000 \mathrm{~m}$, means it experiences a rather cooler climate than would otherwise be expected. This paper represents an introduction to the research and focuses on the province of Yunnan in the area around Kunming.

\section{Climate and Climate Analysis}

The research reported in this paper relates to Yunnan, and both of the village case study locations discussed fall within $100 \mathrm{~km}$ of Kunming. The generalized weather pattern assumes data for Kunming to be broadly valid, particularly considering that the elevation of each example is also close to that of Kunming. An analysis of climate data was carried out using figures from the EnergyPlus energy simulation program website [8].

Overall average temperatures for each month in Kunming lie in the range $10{ }^{\circ} \mathrm{C}-20{ }^{\circ} \mathrm{C}$; however, maximum and minimum averages vary from about $-3{ }^{\circ} \mathrm{C}$ to over $30{ }^{\circ} \mathrm{C}$. The winter of $2015-2016$ brought particularly cold temperatures, which have had a marked impact in the centre of Kunming with many of the tree varieties more suited to warm climates being severely damaged.

The wind direction is generally from the west for January-March and more broadly from the southwest quadrant in the other months of the year. Humidity is at its lowest between February and April with most rain falling in the months of May-October. In recent years, however, the province has suffered from several prolonged periods of drought, which have had impacts on agriculture. 
One method that can be used to identify optimum environmental building techniques is based on bioclimatic design principles; these have developed over recent decades and have been advanced by several authors, including Szokolay [9]. In this technique, the climate data are used to check which design features could be used to help create comfort without the use of artificial heating and cooling systems. The "control potential zones" for each of the several techniques can then be overlaid onto a psychrometric chart (a chart that displays temperature and humidity variations); onto which climate data points have also been plotted. The use of such techniques has previously been studied as part of the SUCCESS project [10] and also in relation to design for different cities of China by groups of students from different parts of the country [11].

The techniques that may be employed in bioclimatic design are generally categorized as: passive solar heating; thermal mass effects; exposed mass and night purge ventilation; natural ventilation; direct evaporative cooling; and indirect evaporative cooling. Figure 2 shows a plot of the climate data and envelopes of the conditions to be address by the techniques (the chart was constructed electronically using the "Weathertool" analysis from the "Ecotect" software package, though analysis can also be conducted in different ways).

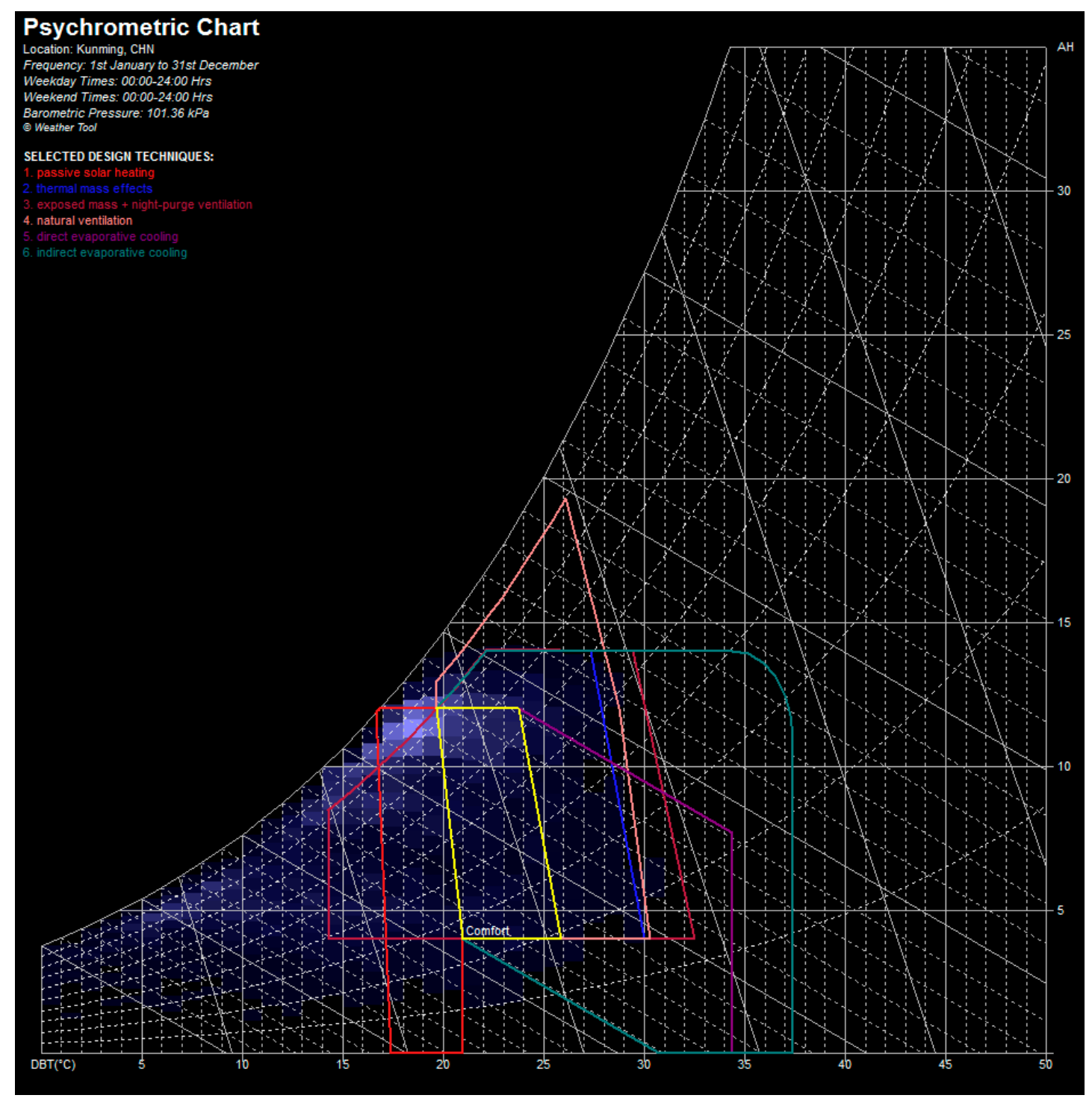

Figure 2. Building bioclimatic chart for the city of Kunming showing the "control potential zones". 
The chart shows that for Kunming, a combination of thermal mass, ventilation and passive solar heating could provide the basis for comfort in suitably-designed buildings, with the addition of a modest amount of conventional heating when temperatures are low. Traditionally-designed buildings in most cultures and climates often incorporate a number of these options or at least have the potential to be modified to include them as part of a vernacular approach. This can be seen through the summary of dwelling architecture presented by Shan Deqi [12], and different cultural influences have also been described by Oliver [13,14] and Rapoport [15]. Buildings and, particularly, dwellings located in the areas of research interest should clearly be encouraged to consider the optimization of the relevant techniques through the use of the bioclimatic approach.

\section{Village Structure and Development Policies}

"Natural villages" are the basic element of rural structure and may trace their history back over many decades or centuries; they have arisen from the natural agglomeration of people and buildings in small settlements. In the south of the country, these natural villages are often small, being similar to hamlets found in other countries; whereas in the north, the typical village size can be larger.

The "administrative village" is a more recent term and represents the formal operating unit for government purposes (that is as the fifth-level Administrative Division) and typically consists of several natural villages collected together and having a population from several hundreds to several thousands (some exceeding 10,000) [2]. Note however that in the north, the largest natural villages have the potential to encompass several administrative villages. There are over 600,000 administrative villages in China.

Crucial to an understanding of village development is an understanding of how they are run at the local level. Historically, the process of the collectivization of agriculture, which took place in the 1940s and early 1950s, created a situation in which the governance and operation of rural areas was led by officials closely associated with the party. The significant outcome of the process was the encouragement and stimulation of agricultural production to meet the country's needs defined by central planning, and this provided rural residents with a modest though secure regular income in the period up to the 1970s. In the subsequent years, a number of reforms were tried in order to stimulate greater production and to meet increasing demands; this involved a number of initiatives to boost efficiency and production, but also led to some confusion. The peoples' communes were replaced by administrative townships and villages, all bound up with the process of decollectivization. As a consequence of this process, some village administrators experienced significant changes in their power and influence, though they retained some important control through responsibility for agricultural land taxes.

In the early 2000s, the national government sought to reduce tax burdens on rural residents and initiated the abolition of the agricultural taxes, which had existed in one form or another for hundreds of years. This process was to be introduced gradually, but in the event was accelerated and planned to be in place by 2006 [16]. The reduction in taxes was to be replaced by funding from other sources; however, an impact has been the changing nature of influence exerted by the previous party-led authorities, over affairs at the traditional village level. There was also the loss of redistributable income to the communities in places where the agricultural taxes were a significant fraction of local government finances (various views can be found in $[17,18]$ ).

The package of initiatives to refocus development in rural areas was announced in early 2006 under the banner of "creating a new socialist countryside" [19]. The expressed aim was to enable residents of rural areas to catch up with their urban dwelling counterparts and to stimulate production from rural areas of those things where they were needed at the national level. This change seemed to recognize both the importance of the countryside and rural areas to complement the urban development that was taking place and also to recognize that not every citizen would live in cities. Indeed, it implicitly shows an understanding that rural areas ought to be successful in support of their more urban neighbours, both to help sustain them, but also to provide for recreation and to 
offer alternatives for longer term and more broadly set development. Liao [2] has however identified some of the shortcomings of village life under present circumstances as including "the lack of basic infrastructure, poor sanitation, environmental contamination, chaotic building form and substandard building quality".

The overall outcomes of the major changes have produced several key focus issues. Firstly, there has been a significant increase in power and influence from the normal residents of villages. This means that support for changes and improvement in conditions depends more than in the past on family groups and local clans within the villages themselves. The leaders are not always from the largest group, and some leaders derive their authority from their management skills and understanding of contemporary matters and technology. One result is that when opportunities for redevelopment of rural villages occur, they can be very much influenced by the attitudes and understanding of the family/clan leaders. A second impact has been to focus the income-generating potential at the household or family, rather than the village level. Linked to this is a third theme, which is the need to seek additional sources of revenue to support village activities from other opportunities, which can then address the lack of some basic amenities in some areas. Alternative business developments and the means to extract value from rural area activities have been encouraged, and a more entrepreneurial approach has been fostered in villages.

\section{Current Structures and Development Issues}

Villages in different parts of China exhibit different characteristics, and this leads to differences in the approach around the likely source or sources of future economic activity. In some cases, this can be based on traditional agriculture or sometimes on the potential for new agriculture and new crops or animal husbandry. The potential for small- to medium-scale industrial activity to develop adds a further dimension, and another significant opportunity arises from the potential to develop tourism (hotels/hostels and food outlets) and tourist-related activity (such as the production of local crafts). This is something recognized at higher administrative levels through the designation of particular villages and the encouragement for tourist potential. A fulsome discussion of tourism in China is provided by Ryan and Huimin [20], and this has also been explored by other researchers, an example being the investigation of a traditional tourist village [21].

Top down approaches coming from outside the village or local area have been prevalent in the past, but such directions of approach face a number of barriers to achieve success. There is often a lack of understanding of the local issues and of the optimum areas for beneficial development or risk areas for failure; and further risk occurs because superimposed solutions do not take account of local physical resources and the skills and knowledge of the local population. There can be some initially successful outcomes, but there is a need to find sustainable solutions lasting into the medium and longer term.

In order to more fully understand the situation, it should be mentioned that there has been a significant difference in the ways in which land is owned and utilized in rural as compared to urban areas. In cities, state-ownership of land is the norm, whereas in the rural areas, ownership remains linked to a previous era with collective ownership still widely found. An important impact flows from these differences, as in cities, it is possible to buy and sell usage rights for development purposes, but in rural village areas, this is not normally possible. The reason for this difference was to avoid speculative purchasing in rural areas; however, many consider that this has hindered beneficial inflows of money and development in rural areas.

Several other consequences followed: there has been, and still is, a tendency for rural to urban migration despite difficulties arising from residency status (hukou); and those who do migrate often face difficulties accessing health, education and other urban-based amenities.

Some changes to rural development processes have occurred, flowing from the Urban and Rural planning policies introduced in 2007 , with villages beginning to have externally-produced masterplans. 
As a result of this, there has been a tendency to agglomerate traditional villages to permit more efficient planning and also the provision of services.

Villages are therefore undergoing processes of revised planning and development; however, although this is picking up in speed and now attracting the wider attention of architects, there is still a lag in the system with perhaps only between a third and a half of villages having developed plans at the present time, though a smaller fraction may be realizable in practice. There can be also difficulties because of the adoption of unrealistic or inappropriate plans. Liao identified this issue [2] and suggested that there were three identifiable problematic situations:

(1) Villages that experience a significant reduction in population and in which there is a level of decay due to a lack of maintenance and the provision of basic services (poor sanitation); in these, many buildings become abandoned, and there may be a high level of environmental contamination.

(2) Villages in which construction is not well controlled, and cheap methods with poor levels of quality predominate (sanitation and contamination again being problems).

(3) Villages located in more affluent areas and in which there are attempts to modernize by introducing features taken from city development: concrete block construction and widened road systems, resulting in the loss of landscape and beauty.

Liao additionally suggested that sometimes, all of these situations could co-exist creating poor outcomes all round. Of course, there can be examples with good features of development, but the author of this paper contends that there is clear scope to develop new supportive (non-binding) policies and advice. These policies and advice could be focused on the future environmental sustainability of villages and act to support the long-term self-reliance and self-support mechanisms that are more appropriate.

\section{Village Case Studies}

Two contrasting villages have been chosen for study in this paper; both are located in the Province of Yunnan and both within a relatively short travel distance of the city of Kunming.

\subsection{Damoyu Village}

Damoyu village is situated between a major road and a scenic woodland area amongst the hills to the west of Kunming city at the edge of Qipshan National Forest Park; its name can be translated from the Yi language as "Bamboo Forest". It is located close to some minor urban areas, including Tian Jie Zhen township to the west and close to the edge of Kunming city itself to the east. Nevertheless, the village seems to be firmly situated in the countryside because of its surroundings and its elevation of $2200 \mathrm{~m}$, which is above that of valleys and Kunming itself. The officially stated population has varied in the last decade from 795-842 residents coming from 242 families each nominally occupying one dwelling [22]. The Yi ethnic group makes up $90 \%$ of the residents, the remainder being Han. Perhaps because of its proximity to other more populous areas, the village has lost a significant proportion of its day-to-day occupants (that is those who would normally be resident in the village each evening), and the normal residents now number only about 300 . The total area of the village is $20 \mathrm{~km}^{2}$, though the residential area is much smaller than this at about $0.75 \mathrm{~km}^{2}$. The village was visited by the author in the spring of 2016 accompanied by one of the leaders of the Sunny Day Sustainable Living Centre, which is attempting to renovate buildings as part of a bigger project that is encouraging self-sufficient lifestyle opportunities in the village based on a permaculture approach.

Data on building types for the dwellings give the following mix: 126 properties can be classified as adobe (earth and mud brick) and timber construction; 95 properties can be classed as predominantly concrete; and 26 properties can be considered to be mainly of timber and brick construction. The survey carried out by the author in 2016 indicated that most of the older-type buildings in Damoyu were constructed from earth bricks or earth walls made from a mix of earth with straw and other materials in traditional adobe methods. Stone is sometimes used in foundation layers, and more conventional 
fired bricks can be seen in some places, such as around windows. Timber is also used as reinforcing and supporting columns and beams in some buildings; it is also used for infill and for doors and window frames and around threshold entrances. Metal doors for main courtyard entrances are also to be seen.

There are a number of modern buildings, some community buildings and shops/eating places together with sports area and communal latrines, but many of the new properties are dwellings. Some are constructed on what appears to be former agricultural land. The new dwellings are a significant contrast to the older style in both scale and materials and with much larger window openings; these tend to be the properties constructed with a significant proportion of materials being made of concrete. An example of the older dwelling type is shown in Figure 3 and of the newer in Figure 4.

An interesting feature of the village, which is known for its availability of water for irrigation, are the channels and tanks, which lie adjacent to some of the tracks that lead from the village reservoir to some of the fields (Figure 5a). Interestingly, along many footpaths between the houses, and in contrast to the agricultural irrigation, are plain unprotected metal water pipes carrying domestic water supplies to dwellings (Figure 5b). There was no obvious system of foul water collection and disposal or evidence of significant waste collection facilities or disposal systems.

As a symptom of the loss of day-to-day residents, it seems that the tending of the agricultural land is now often taken on by the older generation (Figure 6). It is clear from casual inspection that many of the older traditional buildings have unmet maintenance needs, though many are habitable on a basic level. The deterioration of the adobe brick structure and ingress of water seem to be the major difficulties. Figure 7 shows some of the dwellings exhibiting deterioration, and Figure 8 shows a property undergoing renovation using some of the traditional techniques.

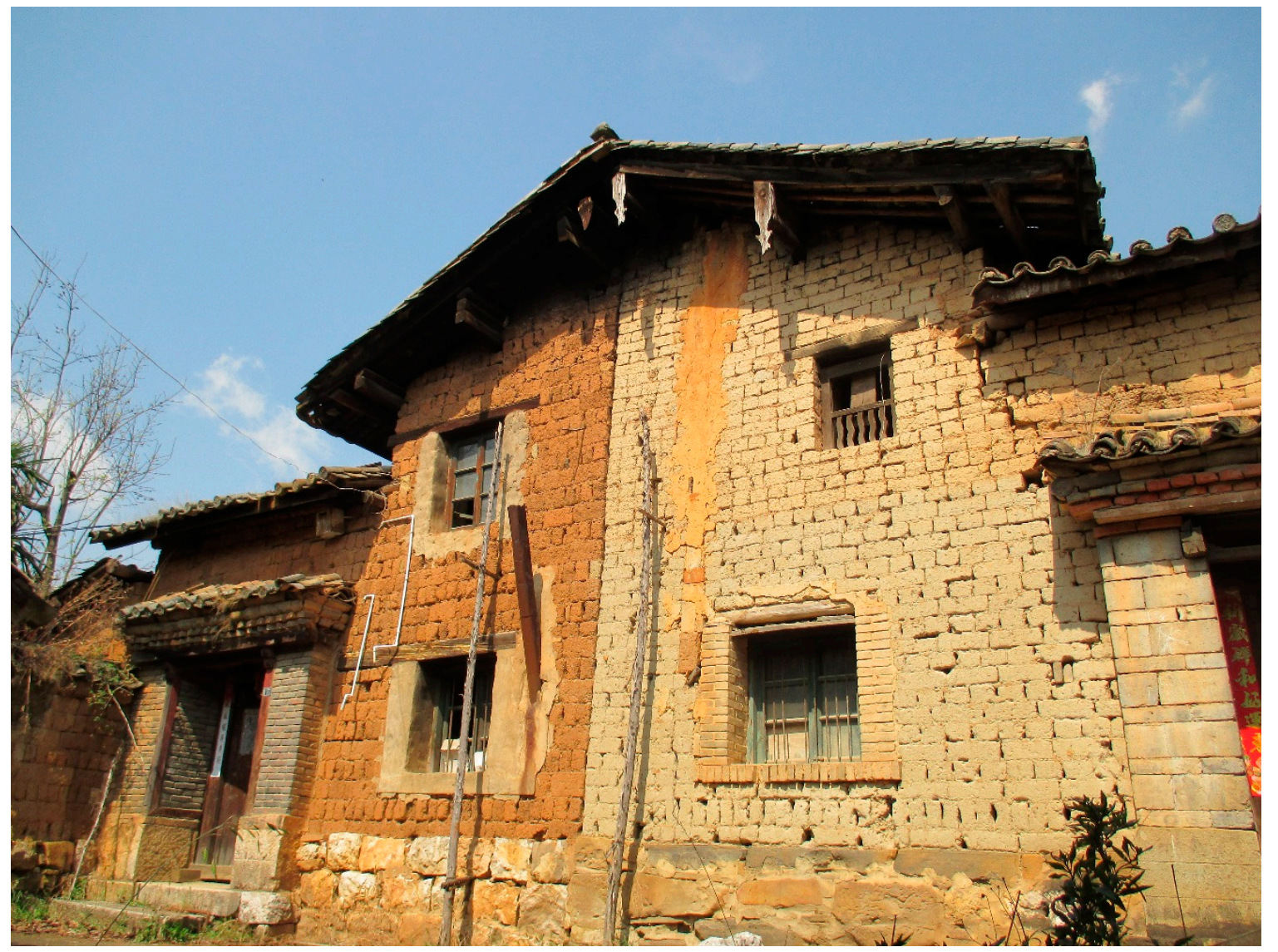

Figure 3. Damoyu traditional construction dwelling. 


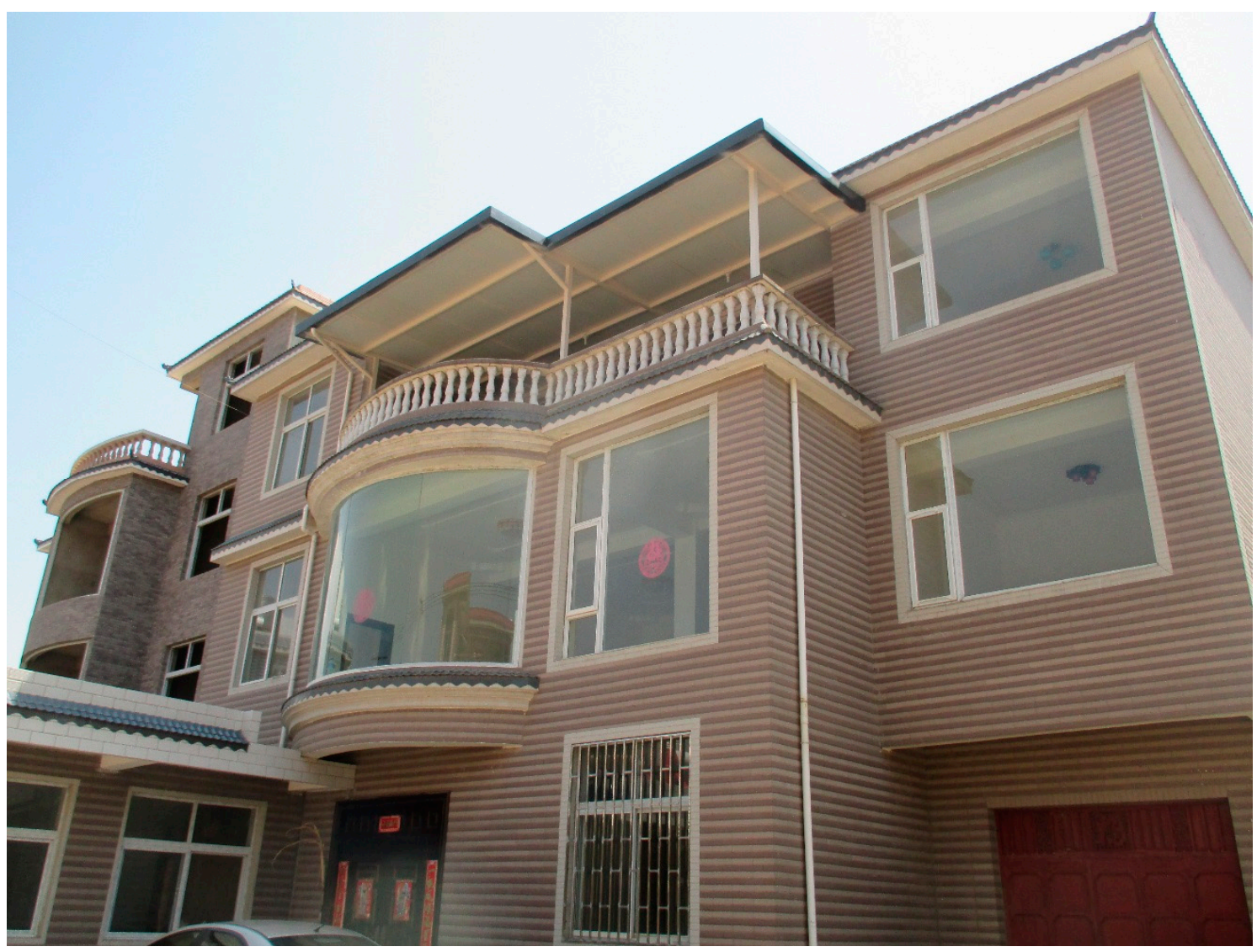

Figure 4. Damoyu new construction dwelling.

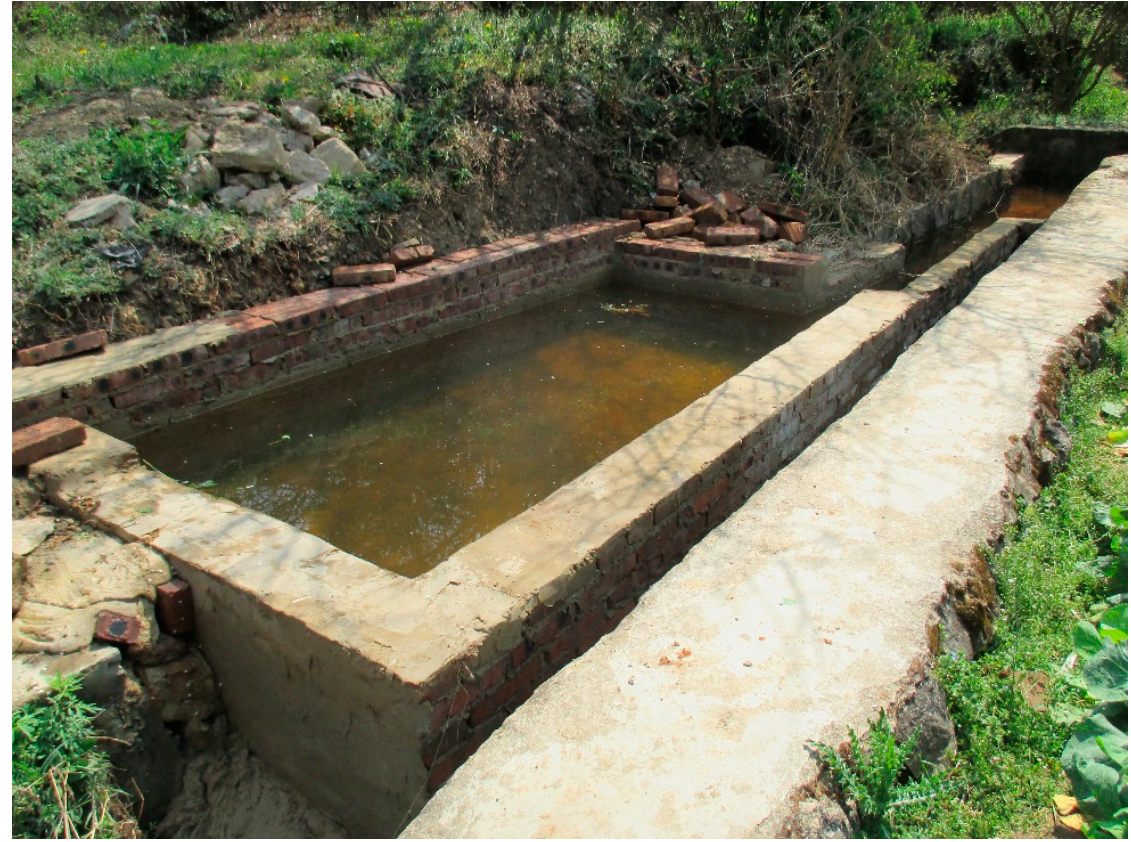

(a)

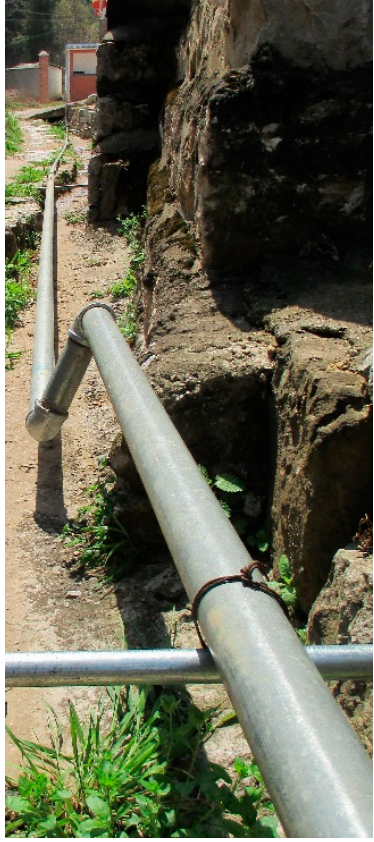

(b)

Figure 5. Damoyu water systems: (a) agricultural irrigation tank; (b) domestic water supply pipe. 


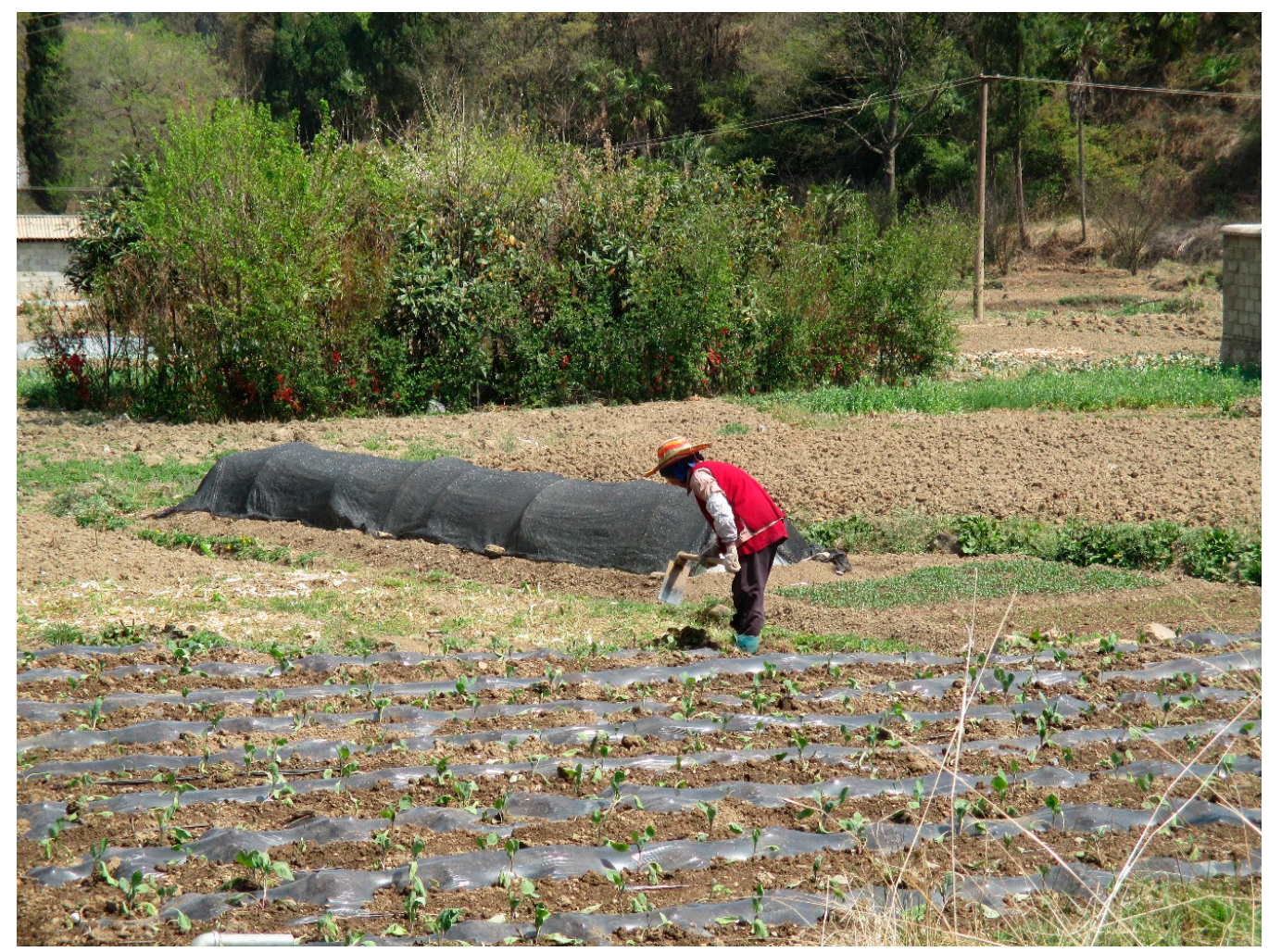

Figure 6. Damoyu older resident working the agricultural land.

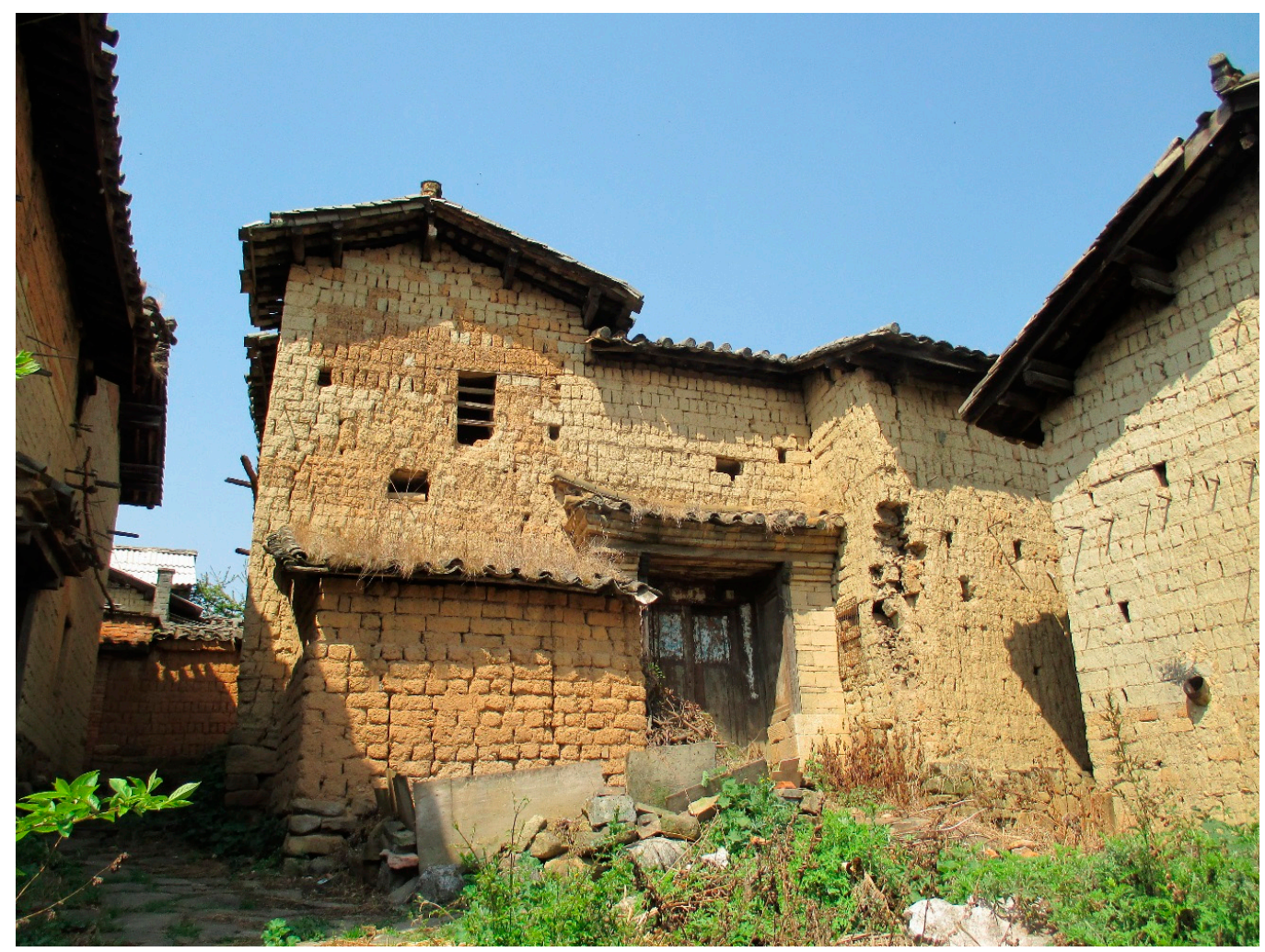

Figure 7. Damoyu deteriorating building. 


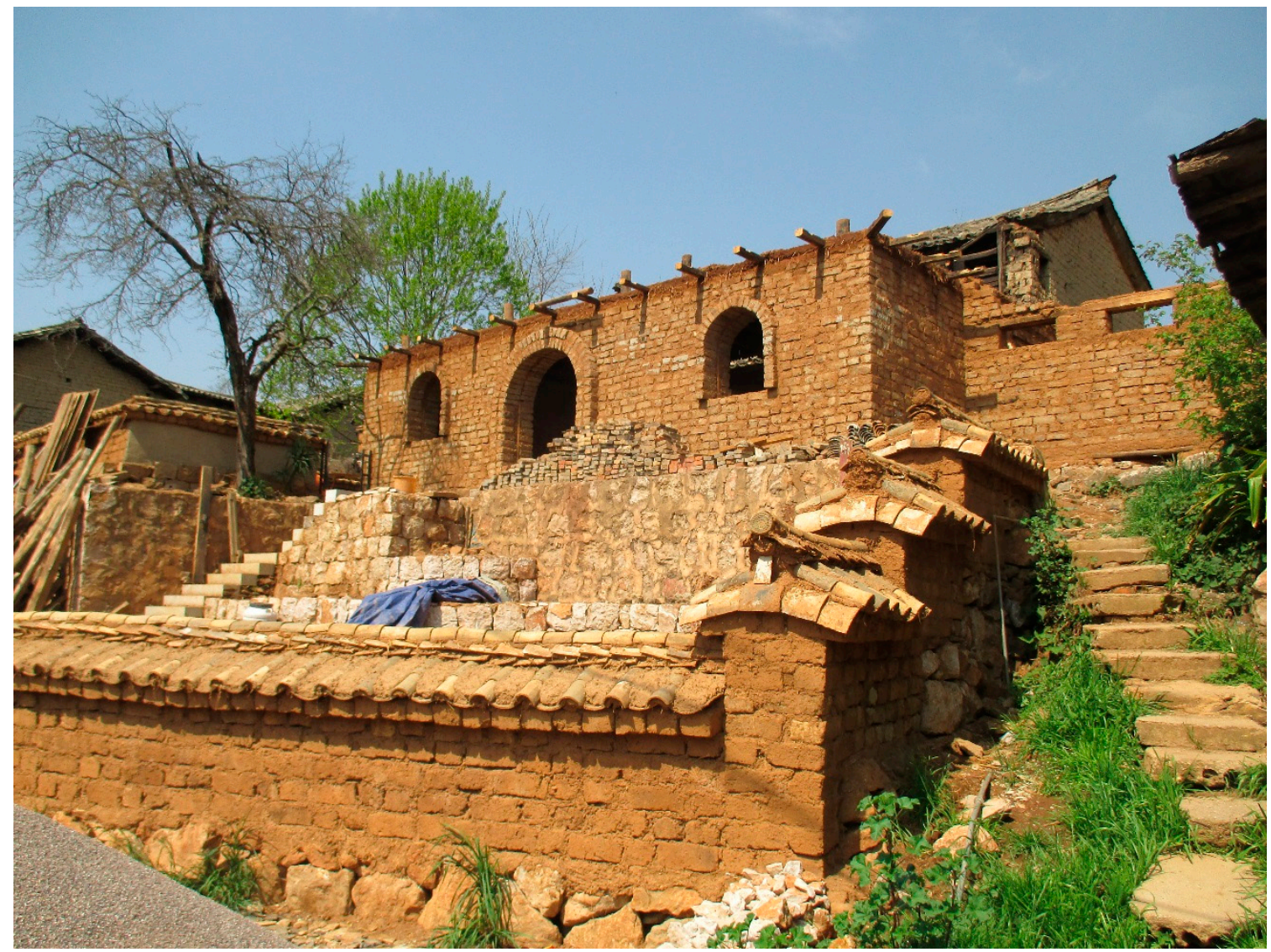

Figure 8. Damoyu building renovation project.

Analysis of the traditional buildings shows internal layouts to have the majority of windows and openings facing in one orientation. The majority face to the east given the slope of the land and towards the main surfaced roads through the village. Many of the new dwellings face from the other side of the road towards the west and have rather more windows. The use of modern materials of concrete and bricks seems to have promoted the adoption of large glazed openings in a number of cases, also clearly seen in Figure 4. From the on-site survey of both new and old dwelling construction, it appears that improvements to performance might be found relatively easily if more attention were focused on window positioning, size and function, taking account of exterior features and the internal space needs.

\subsection{Nuohei Village}

Nuohei is a village of about 1500 residents situated to the east of Kunming in Yunnan Province, and it is in the Stone Forest area. The Stone Forest is a popular tourist destination consisting of spectacular formations of Karst limestone, which create a landscape drawing many visitors. Many of the villages in the area are constructed using forms of the same limestone, and Nuohei is no exception with $98 \%$ of dwellings built using stone [23]; indeed, the village is also known as the "Stone Village". The author visited the village in the spring of 2016 and was able to collect information about its buildings, culture and history; some of the details that follow are derived from the collections in the Nuohei Ethnic Cultural Museum situated in the village.

The village belongs to the Yi nationality group and specifically the Sani subgroup in Shilin County; there are 392 families and with 99\% from that ethnic grouping [24]. The village was founded over 600 years ago and is situated approximately $2000 \mathrm{~m}$ above sea level on the plateau of central Yunnan and has a sub-tropical monsoon climate. The area is hilly, though not mountainous, and 
communication routes by road are relatively good. The total area of the village is almost exactly double that of Damoyu at $39.8 \mathrm{~km}^{2}$, and $86 \%$ of the ground is covered by land designated as forest [24]. The village is quite well known for its features and appearance, and in 2007, it was specified as the first "tourist" village in the area. It has also been a key site for anthropological investigation [25].

Nuohei is a village founded on agriculture; however, it has developed a new focus in recent years with its tourist destination designation and with significant numbers of groups visiting (dining facilities for up to 300 people being available from the combined input of five families [26]). The widespread use of stone has created an environment that has attracted artists to both live and work there. This together with more general tourism has helped develop a number of businesses catering to them. This is evident in terms of visitor accommodation and shops in a greater number than would be required for residents, as well as encouraging local groups to exhibit their traditions of embroidery and folk dancing, amongst others.

The name Nuohei derives from the words for "monkey/ape" and "pool", and the village museum suggests the interpretation should be "a scene in which apes lead happy lives around the pond" [24]. A prominent feature of the village is its lake on the east side of the village centre and towards which many of the properties face; see Figure 9. Figure 10 shows a group of typical dwellings. Historically, the key agricultural products associated with the village have been tobacco and maize, and this has impacted the buildings and structures to be found there. There are numerous tall tower-like windowless structures, which are used for drying tobacco leaves (Figure 11), and spaces for storing maize can be found almost everywhere, both on the outside and the inside of buildings (Figure 12 shows the maize against shutters of upper floor windows).

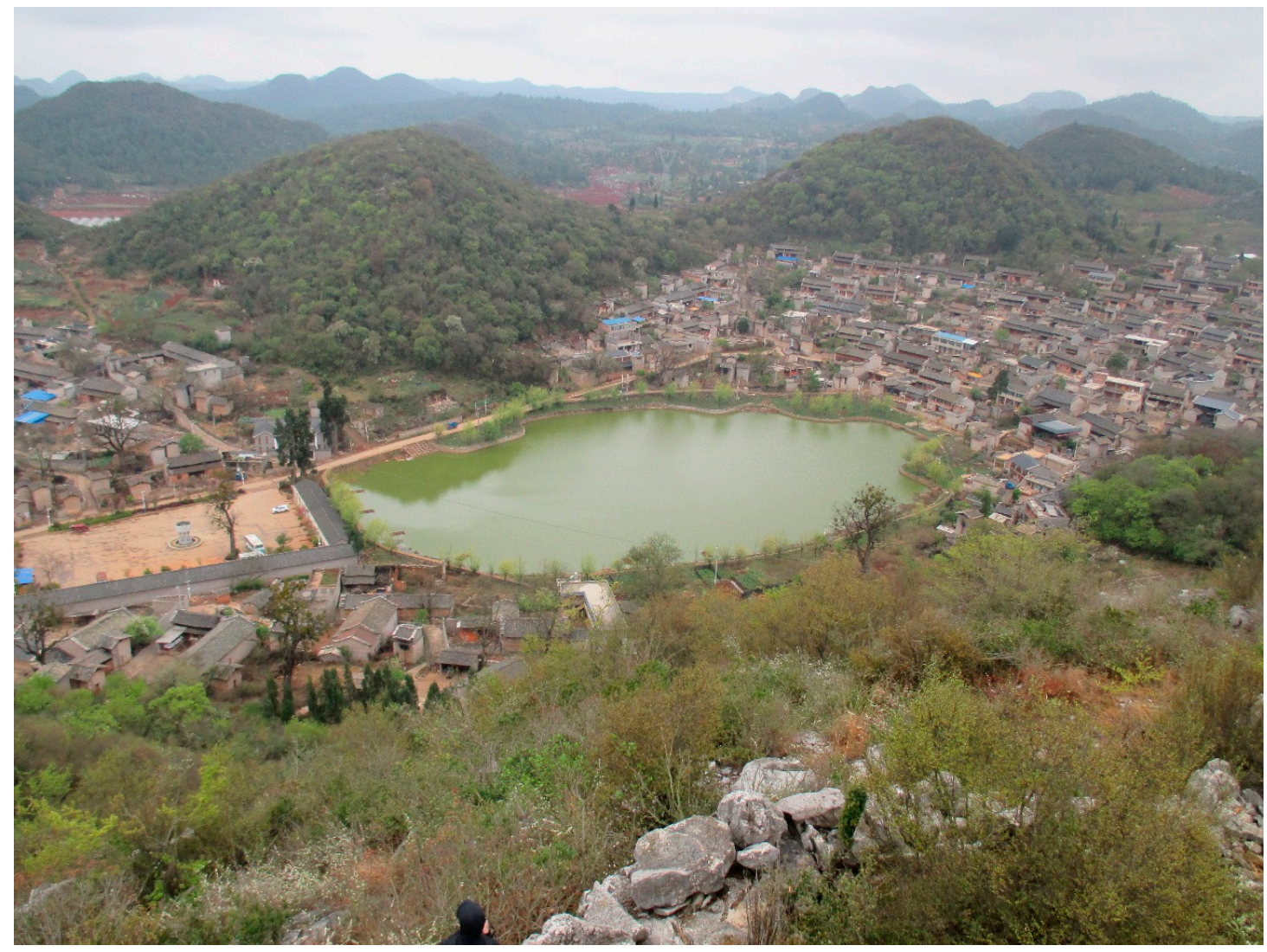

Figure 9. Nuohei: view of the village. 


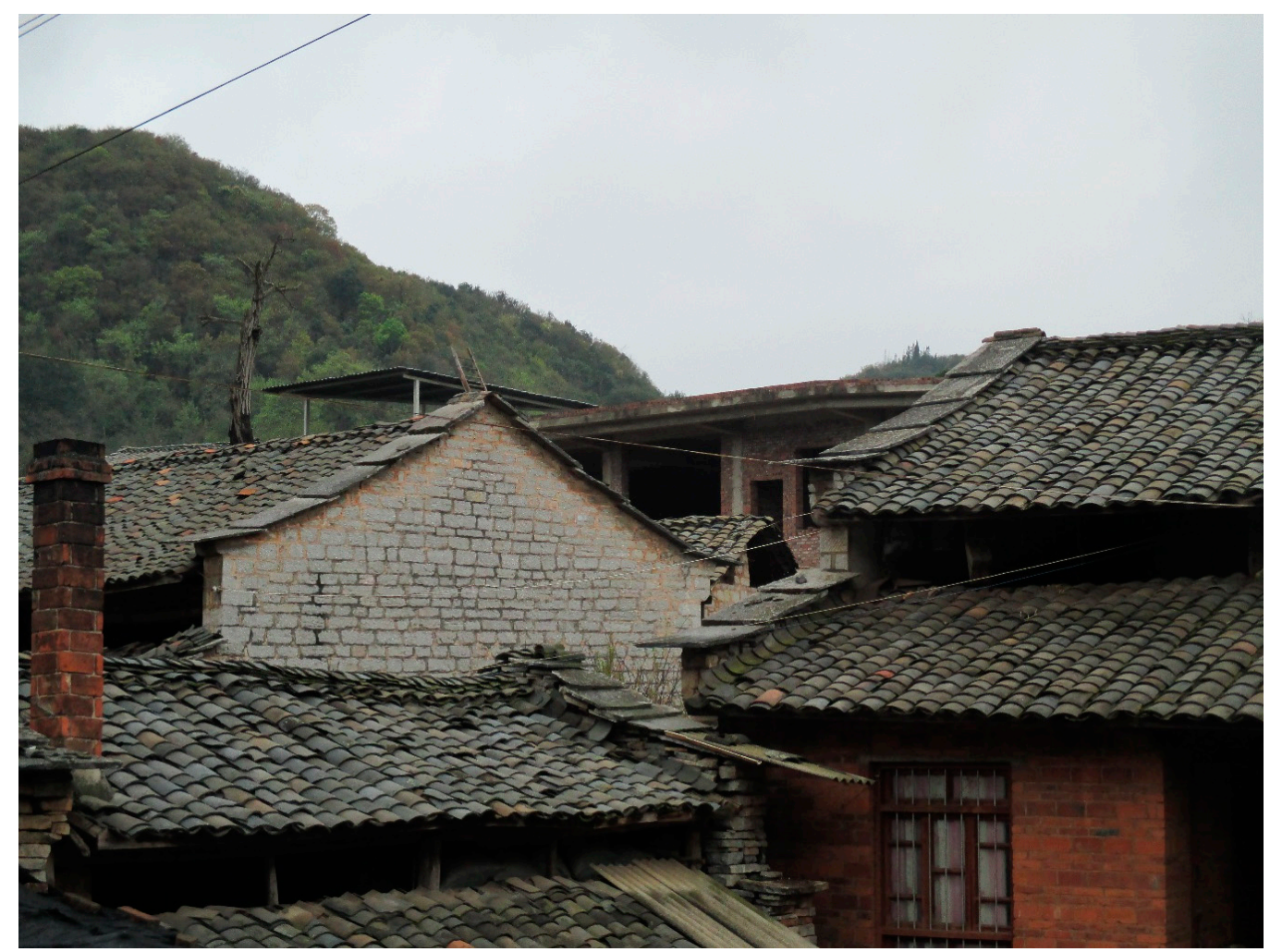

Figure 10. Nuohei traditional stone dwellings.

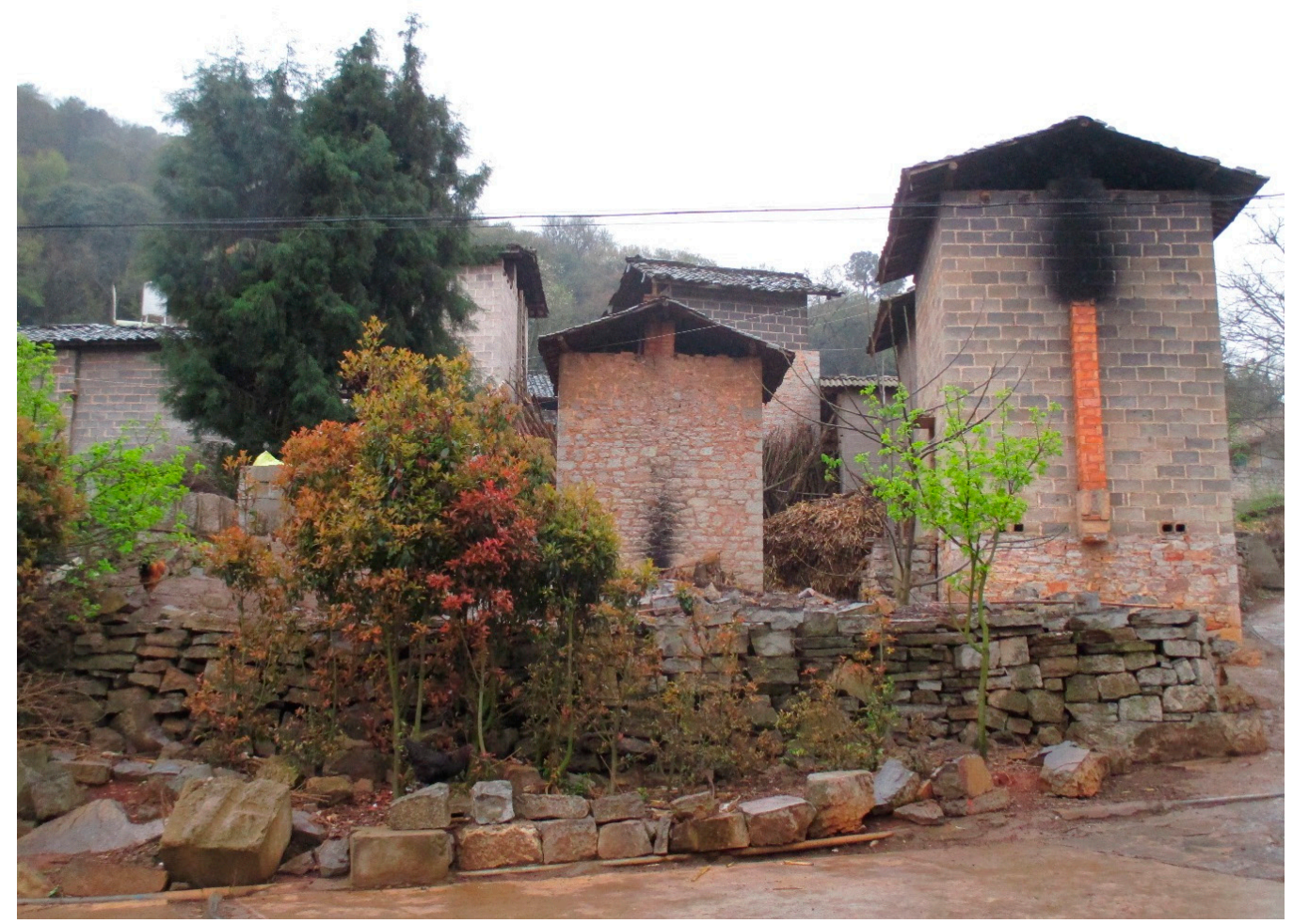

Figure 11. Nuohei tobacco drying towers. 


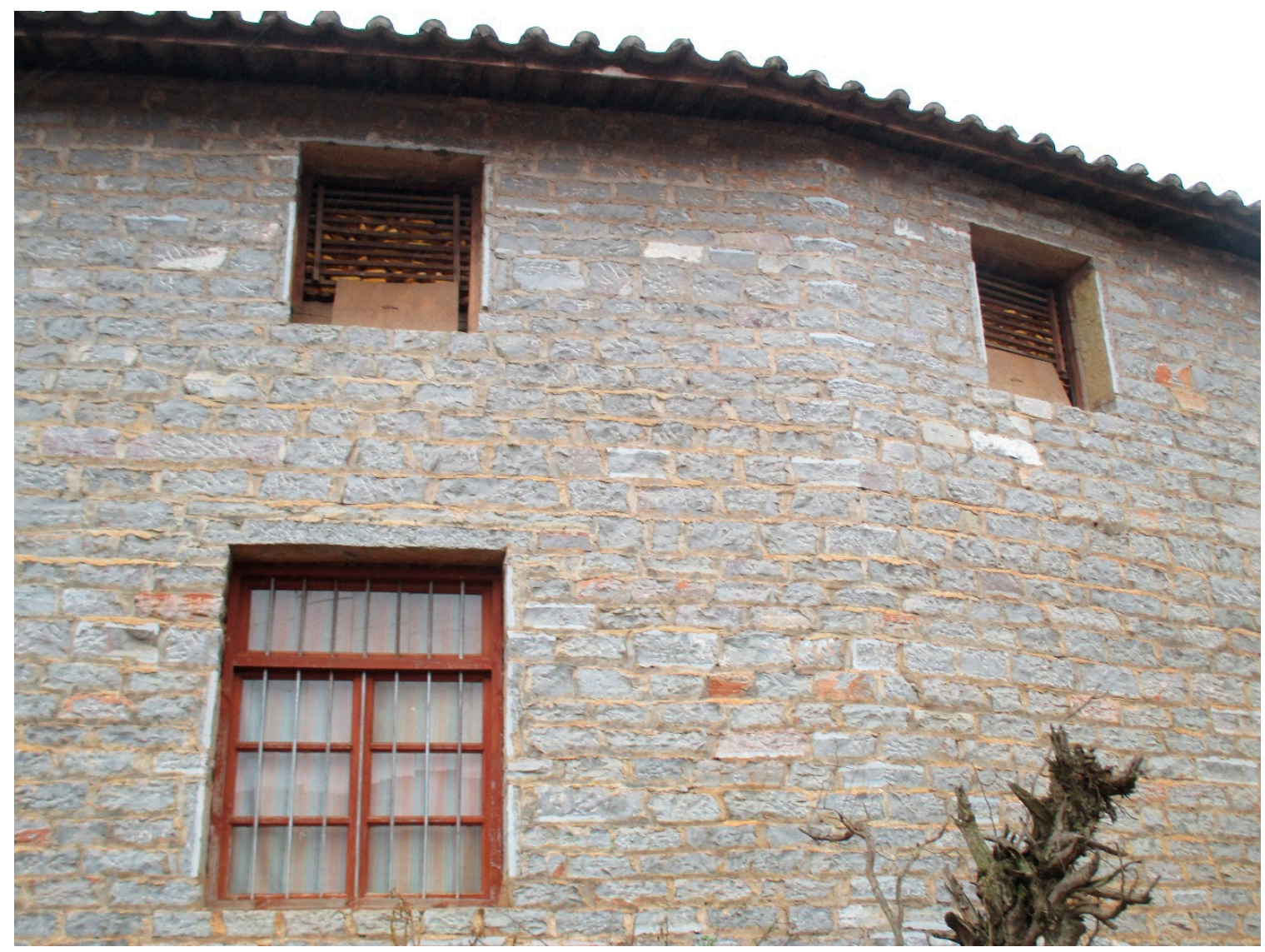

Figure 12. Nuohei maize storage on upper floors.

The village is prosperous with places to eat and buy products, as well as places to stay, each of which are advertised on the posters in the main car parking area and on numerous signs through the village in both Chinese and English. There is a propensity of motorized transport (though many vehicles are those designed for agricultural purposes), and there is a thriving village school. The village emphasizes traditional development focusing on preservation; it follows strict guidelines for the protection and management of intangible cultural heritage and of the environment. It was declared a region for the protection of the Sani Yi culture by the state in 2006.

Turning to the buildings themselves, in contrast to the traditional adobe buildings of Damoyu, they are constructed from stone set in many different patterns. Figure 13 shows a collage of styles, including both stones and bricks, which can be seen walking along the main street of the village. The majority of buildings are in a good state of repair, though it is also clear that some maintenance is required in a number of cases. Many buildings also make use of timber and other materials, as well as, of course, glazing. There is no clear evidence of the use of modern insulation materials. Those buildings constructed using similar adobe materials to those of Damoyu seem to be in a poorer state of repair than those constructed from stone. There also seems to be an increasing use of concrete blocks for construction, particularly for the agricultural buildings. 


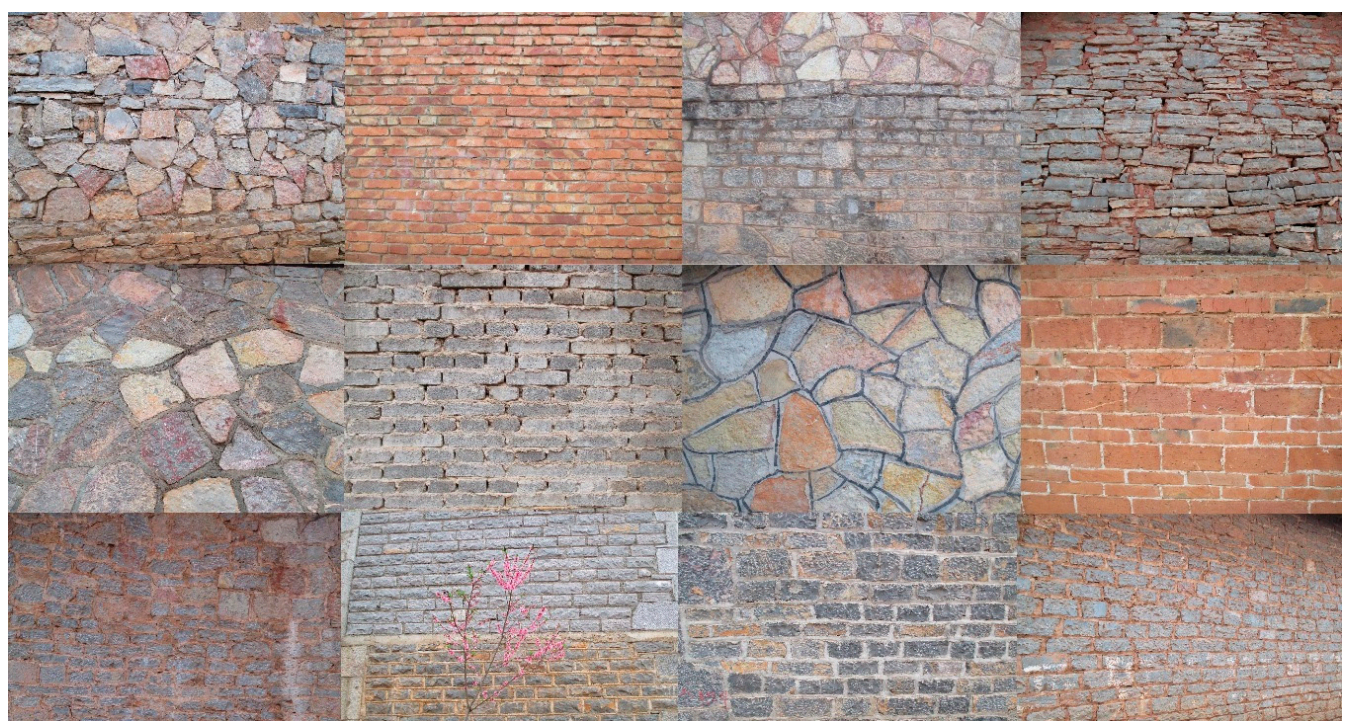

Figure 13. Nuohei: collage of twelve different wall constructions.

Glazing and window openings are more evenly distributed than in Damoyu, though still limited in many of the older buildings. The slope of the village towards the lake tends to encourage windows on the more open east-facing façade, and though the more recent modern buildings have more restrained window sizes (by comparison with Damoyu), they are clearly recognizable as being from a different time period than the historic stone dwellings (see Figure 14). There was little or no evidence of modern heating or cooling systems.

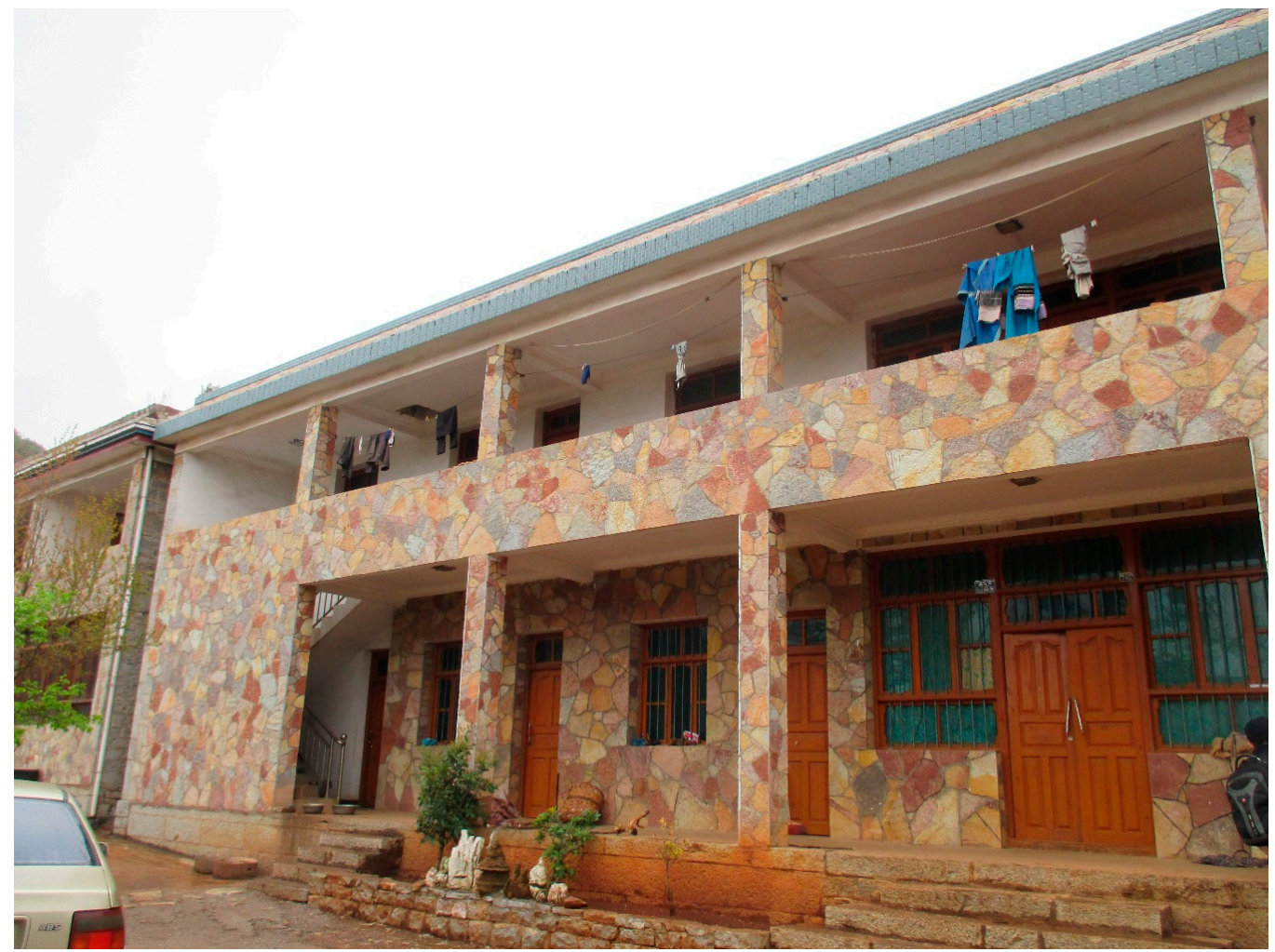

Figure 14. Nuohei modern building. 
Nuohei is a relatively successful village with some strong features that favour it from economic and cultural perspectives. Some questions may be asked however about how its environmental sustainability could be improved and maintained. Components of the main constructions (walls and roofs) seem relatively simple, offering opportunities for design variation to optimize heat transfer and, thus, internal environmental conditions. Furthermore, as with Damoyu village, although window sizes seem more appropriate, the on-site survey suggested opportunities for better configuration and location.

\section{Village Building Design Issues}

Rural villages in China have been studied by many researchers, more often from ethnographic and cultural perspectives. The architecture and design features have also been analysed as previously mentioned; the research reported in the SUCCESS project $[7,27]$ indicated that the variation in traditional design across the range of villages considered was less than might have been expected. The main dwelling type studied was the courtyard format, and perhaps, this in itself restricted the degree of variability, since only relatively few buildings were studied. The occupancy of different rooms facing the courtyard might vary, and routes through the courtyard and its connectivity were found to vary; however, the underlying features that could have modified the environmental design did not. Materials used for the dwelling seemed to be locally sourced and could therefore be interpreted as coming from a restricted palate, which might also have limited adaptations.

The research reported in this paper does however show that rural village design has begun to change, and it is suggested that this is linked to the changes to administrative hierarchies and policies, which have released the villages and their occupants from the previous restrictions. It is therefore a very opportune time at which to discuss further the processes needed to encourage and direct improved environmental design of buildings and also, as a consequence, to improve overall sustainability. Although the two villages featured here have a number of differences from a cultural perspective, they also have a number of similarities in terms of their environmental responses, which enhance and hinder optimal environmental design; four aspects are discussed in the following paragraphs.

Firstly, building materials impact heat transfer for the buildings; this is an important factor for buildings in which there are few if any efficient heating systems. The predominant materials used in each village example are significantly different, and though Yunnan has a relatively benign climate, there are times in the year when cooler temperatures are experienced; and it is at these times that thermal performance becomes important. The use of insulation materials is not in evidence, and there are few examples where more sophisticated component design can be found. The newer buildings in Damoyu do not seem to respect the old patterns so rigidly, and there is certainly the potential (because of the more diverse plan) in Nuohei to optimize the orientation of the building so as to try to make more use of passive solar heat gain. Changes to the physical construction of new buildings could involve the incorporation of more insulation and other properties to optimize heat transfer. The renovation of older buildings will be a challenge (as it is already in many parts of the world); however, the use of techniques most suited to each example should be investigated.

Secondly, window sizes, orientations and opportunities for light penetration do not seem to have great clarity in design. The orientation of windows is generally led by the orientation of the main street and lane patterns, which in turn may be determined from external factors. Further, the norm in all but some of the more extravagant modern buildings is for the use of a single orientation for windows in a room and often the whole building; this limits natural light penetration and encourages the use of artificial lighting inside. In some buildings, however, the only light-admitting opening into a room is a door. Passive solar heat gain opportunities are also less than optimal in these circumstances. The opportunity for optimizing performance therefore exists.

Thirdly, ventilation considerations do not seem to be well developed in either village in terms of providing for fresh air for occupants or to address air circulation with respect to summer cooling potential. This goes hand-in-hand with the issue of daylight admission and could be a particular 
issue when doors are left open for light, as air flow cannot easily be controlled in such circumstances. Natural ventilation is at its most useful when there are potential openings located on two (ideally opposite) façades of the building and, where possible, that the opening locations take into account prevailing wind directions (in Yunnan, the wind direction for most of the year is from the southwest quadrant, though modified locally by flow along valleys and around hills).

Fourthly, the integration of the above issues into the orientation and design of courtyards, which are found in many of the traditional buildings of both villages, is not clear. The ways in which courtyards are designed is explored by Shan [12], and there are good explanations for the impacts of ethnicity in Wang [4]. Some potential benefits that could be maximized through the use of courtyards include: the creation of openings for increasing the natural lighting of the spaces; the optimization of solar gains; and the potential to create new openings to permit cross-ventilation. There is currently a lack of evidence, especially when considering more recent buildings, as to how these issues are considered or incorporated.

In identifying the above issues, the author is therefore very well aware of some of the overarching considerations arising from cultural and historical determinants of building design and orientation, as well as placement within the landscape. Feng Shui and ethnic cultural traditions may create a propensity for locating buildings with their backs towards hillsides and mountains and facing towards water. Such traditions can, and do, have a role, and the research here indicates that opportunities might be sought to understand better the influence of history and culture on environmental design in villages and also, in parallel, how occupants themselves seek to use interior design to optimize their dwelling spaces [28]. Future analysis and development should take due account of the specific needs for the preservation and maintenance of those things of interest to visitors and tourists, as well as the indigenous population, but it could also act to inform local populations of the impact of variations in design on the environment and comfort in and around buildings.

\section{Sustainability Assessment and Prioritization}

Factors enhancing sustainability linked to improved environmental potential arising from planning and design strategies have been reported in various studies $[29,30]$. There are a number of assessment and rating systems available in different parts of the world, which both identify key features of building and neighbourhood design, which are relevant to achieving sustainable communities and also which help to provide some evaluation methodology. Knowledge of these factors can therefore help to produce priorities for consideration in design.

One of the ways in which stakeholders are enabled to make better and more well-informed decisions is through guidance produced from using standardized (but appropriate) assessment and ratings tools. There are also a number of internationally-recognized schemes, such as the U.K.-originated Building Research Establishment Environmental Assessment Method (BREEAM) [31], which can be adapted to different countries and climates, and the Leadership in Energy and Environmental Design (LEED) system [32], which began in North America supported by the Green Building Council, but is widely used in other countries, as well.

There are a number of limitations to such techniques, however, including the fact that whilst they allow comparisons, they are not well adapted to be able to provide design guidance because they do not align in any simple way to the design process itself [33]. A further criticism is that they have been developed in countries and locations far removed from southwest China. They (along with the majority of techniques currently available) have been developed to deal with modern buildings located in urban or semi-urban areas. Overall, then, they are less applicable to the geographical focus of this paper, and the situation of rural villages in southwest China requires some special consideration because of the ways in which decisions about dwelling design and construction are made.

A previous more generic review of the criteria for sustainability assessment derived a base list of themes (shown below), which would form part of a strategic planning approach to achieving sustainability at the neighbourhood scale [29]: 
- Built environment, including the size and placement of development; building types; density; landscape and ecology

- $\quad$ Energy systems

- Transport systems

- Water systems

- Wastes and pollution

In addition, the provision of information for stakeholders was also identified as a clear additional requirement in order to allow them to make sensible decisions about priorities and, then, the appropriate technologies and techniques to be used. It is also clearly important to make the optimum choices related not just to the present circumstances, but also to consider future changes, particularly those that arise from: variations of energy/fuel mixes; the availability of systems that might be needed to service buildings; and also, from climate change. The "futureproofing" of buildings has been advocated by several researchers over recent years (see, for instance, [34]) as a means to provide robustness to design.

Researchers at the Chinese University of Hong Kong [35] have also suggested the means and focus to develop a suitable tool for rural China, the Rural Built Environment Sustainability Assessment System (RBESAS). In this system a framework was developed based upon two key themes: self-reliance capability and development capability. The key elements are shown in Table 1; one potentially significant omission from the list is materials, though it is included within sub sections.

Table 1. Rural built environment sustainability assessment system (from [35]).

\begin{tabular}{cl}
\hline Theme & \multicolumn{1}{c}{ Sub-Element } \\
\hline & Land and resources conservation (sensitive areas; agricultural land; soil; and water) \\
Waste management (construction and demolition; operational) \\
Pollution control (construction and demolition; agriculture) \\
Food (production of local food; diversification of farming) \\
Water \\
Self-reliance & Housing \\
& Safety and security \\
& Health and well-being \\
& Energy \\
& Economy \\
\hline & Sustainable landscape \\
& Sustainable agriculture \\
& Culture and context \\
& Inclusiveness and participation \\
& Education and information \\
\hline
\end{tabular}

As part of the research for the current project, discussions were held with a variety of stakeholders located in the region of interest over several visits to China. These established that at the village scale (either natural village or administrative village), there is little knowledge or understanding of what the use of broad assessment techniques involves or what benefits might accrue. There is a separation between the practical day-to-day functioning and development of a village at the local level and what might be seen from a higher administrative or profession perspective. Professions such as architects involved in the redesign, re-zoning and redevelopment of villages with whom conversations were held showed understanding of the larger scale sustainability scenario, but not of how specific changes to building design and construction could make significant and worthwhile differences. Issues such as the comfort and energy efficiency of buildings within the villages seemed to have a low priority, and there is a scarcity of information and a lack of access to suitable support systems. National eco village standards and other building standards do exist, but these seemed not to be having a tangible impact in areas where key improvements could be made to design and construction. There is however 
a growing body of research into optimizing environmental conditions and comfort in rural dwellings (for example, [36]).

The outcome of the review of methods indicates that whilst they have value in different ways to different stakeholder groups; that is, for use with and by local residents, advice for village and dwelling level environmental design was required.

\section{Recommendations for Village Environmental Design}

One of the conclusions of Liao's research [2] was the need to produce and adopt some form of design guide. In his research, the design guide would have been focused on a number of issues and would have included the details of the appearance of buildings, streets and neighbourhood. This approach is generally supported by this author; however, the primary aim of this research is to consider the environmental performance and comfort of buildings and, particularly, dwellings, which means taking a more specific approach. A design aid with a focus on a limited number of elements, but elements that are crucial to the success of rural building redevelopment, is strongly advocated. Heat transfer, daylighting and ventilation were important environmental design aspects identified above.

A number of researchers have attempted to devise systems for design support based on the analysis of influencing factors (see, for example, [37]), and the evolution of a system based on a reduced set of features is the basis for the proposals that follow. The environmental features of buildings with the most impact on energy flows (heat gains and losses), daylight admission and air movement are those that must be incorporated in design support systems and in ways that are accessible to local stakeholders. From the interviews carried out by the author with a selection of stakeholders and from a review of current rural villages, some priorities are identifiable, and flowing from this base analysis, there are three building design elements that have clear and significant impacts:

(1) Orientation and site placement; linking to sunlight and to wind flows and including the spacing between buildings

(2) Windows and openings' design; linking to daylight/sunlight penetration and ventilation

(3) Construction of walls, roofs and floors; linking to the impacts of thermal insulation and thermal mass

Each of these has been appraised in terms of its potential to impact the six passive strategies previously identified in relation to Figure 2. If in addition to those six, a further feature of restricting thermal heat flow is added, then an analysis of the impacts of the three elements of the building can be derived as shown in Table 2. The impact values were derived from a process that used outcomes from research into design options [11] and also information gathered from interviews of professionals working in Yunnan Province. These impact outcomes in the table will be analysed and verified further in the next stage of the project, but form a valuable basis for advancing the research at this point.

Table 2. Impact of selected building elements on passive feature performance.

\begin{tabular}{cccc}
\hline Design Feature & Orientation & Windows & Construction \\
\hline Restrict thermal heat transfer & low & medium & high \\
Passive solar & high & high & medium \\
Thermal mass & medium & medium & high \\
Natural ventilation & high & high & low \\
Mass + night purge ventilation & medium & high & medium \\
Direct evaporative cooling & medium & medium & low \\
Indirect evaporative cooling & low & medium & low \\
\hline
\end{tabular}

${ }^{1}$ Orientation and windows impact thermal mass effect due to the control over solar heat gain. 
The priorities from this table can therefore be used to inform the preliminary development of a design aid for rural buildings (particularly dwellings) that would enable the impact of parametric variations in the three key elements to be incorporated. The final form of the design aid is still under development; however, it is evident that the element with the greatest impact is likely to be the window design with three "high" and no "low" impact values. The multiple function of the window includes control of daylight admission; control of solar heat gain; control of thermal heat loss; and control of air ingress impacting air flow around rooms/building (and thus human bodies) and for ventilation/fresh air.

This focus on the window has some similarity to the focus of previous research giving guidance on this critical element of building design, a prime example being the LT (lighting and thermal value of glazing) method [38] devised by Baker and Steemers and their collaborators almost two decades ago. It is also the most appropriate element that can be modified in the upgrading of existing buildings and the element that seems to have become the most visible feature of new buildings. The development and evaluation of a design aid based on those elements is now required, and the development of a system with some of the most useful feature of the work of Baker and Steemers will now be taken forward in the next stage of research.

\section{Conclusions}

The new developments taking place in rural China encompass the design, construction and the redesign and reconstruction of village buildings. The extant situation has come about following a long period of evolution dating back to before the advent of the modern Chinese state and through periods of significant change. For several decades, the preoccupation of those involved with design and construction has been with urban city-scale development; however, now, for the first time, there is an opportunity to make use of up-to-date technologies and techniques and their evaluation in situ to enable sustainable environmental rural building development.

This paper has reviewed the historical basis from which the current situation arises and also the varying contemporary influences. From this, it has been concluded that there are real needs and real opportunities for better rural village development. Sustainable rural village development does need the three aspects of sustainability (economic, social and environmental) to come together in an effective way. The author's observation however is that without a key environmental support system, the others cannot effectively function given the current relationships between stakeholders.

The need has therefore been identified for a simple and rational design aid to support rural residents, architects and planners, as well as other stakeholders; this being used to improve and optimize a limited, but important range of design features. Those features determine heat flow, daylight and ventilation, and the relevant design elements can be defined as: orientation and site placement, window design and construction.

An important aspect of the research development has been processes to ensure relevance to rural villages in practice. The two villages described in the paper provide a range of contrasts, which are indicative of the scope and challenge. Each village has a significantly different occupancy pattern and also a difference in the level of prosperity; both of these factors linked to the employment type and location of the normal village residents. The construction of buildings within each village also varies significantly, and this has clear implications for the construction techniques and on environmental conditions likely to be created inside the buildings. A common theme of both, however, was the potential to improve window and opening design.

The basis for environmental design support is now in place, and development will occur as a feature of the larger research project of which this paper forms a part. The development phase involves the following: working with architects, planners and academics in rural southwest China; linking with local area administrators and village groups and activists; development and testing of the design support system; engagement to explain how the system can be used and its benefits with stakeholders; formalized trials and testing; and then, the reporting and evaluation of the impacts. 
Acknowledgments: The help and support of the staff of Yunnan Arts University, Kunming, facilitated access to the villages mentioned in the study and provided useful background information.

Conflicts of Interest: The authors declare no conflict of interest, and there are no sponsors having a role in the design of the study; in the collection, analyses or interpretation of data; in the writing of the manuscript; nor in the decision to publish the results.

\section{References}

1. Riskin, C. United Nations Development Programme. In China Human Development Report 1999: Transition and the State; Oxford University Press: Oxford, UK, 2000.

2. Liao, H.; He, H. Developing smart and green rural settlements for the rapid urbanizing China: Experienced learnt from England. In Proceedings of the 8th Conference of the International Forum on Urbanism True Smart and Green City, Incheon, Korea, 22-25 June 2015.

3. Zhang, G. Shanghai Daily, Shanghai-Kunming Railway nears Completion. Available online: http://www. shanghaidaily.com/metro/public-services/ShanghaiKunming-railway-nears-completion/shdaily.shtml (accessed on 20 June 2016).

4. Wang, X. Architecture of Chinese Ethnic Minority Groups; Ethnic Cultures of China Series; China Intercontinental Press: Beijing, China, 2007.

5. Times of India. China Wants to Revive Southern Silk Road with India. 9 June 2013. Available online: http://timesofindia.indiatimes.com/business/international-business/China-wants-to-reviveSouthern-Silk-Road-with-India/articleshow/20510534.cms (accessed on 20 June 2016).

6. Gao, Y. Being There-Reflections on 20 Years of the International Course at the Huddersfield Department of Architecture; University of Huddersfield: Huddersfield, UK, 2010.

7. Dumreicher, H. Chinese villages and their sustainable future: The European Union-China-Research Project "SUCCESS". J. Environ. Manag. 2008, 87, 204-215. [CrossRef] [PubMed]

8. EnergyPlus. Weather Data. 2016. Available online: https://energyplus.net/weather (accessed on 23 June 2016).

9. Szokolay, S.V. Introduction to Architectural Science-The Basis of Sustainable Design; Routledge: London, UK, 2014.

10. Bouillot, J. Climatic design of vernacular housing in different provinces of China. J. Environ. Manag. 2008, 87, 287-299. [CrossRef] [PubMed]

11. Pitts, A. Prevalence and evaluation of bioclimatic design techniques used to achieve low energy comfort in architectural design proposals. In Proceedings of the Windsor Conference: Counting the Cost of Comfort, NCEUB: Network for Comfort and Energy Use in Buildings, Windsor, UK, 10-13 April 2014; pp. 1078-1090.

12. Shan, D. Chinese Vernacular Dwellings: People Daily Life with Their Houses; Dehua, Wang, Translator; Cultural China Series; China Intercontinental Press: Beijing, China, 2010.

13. Oliver, P. Encyclopedia of Vernacular Architecture of the World; Cambridge University Press: Cambridge, UK, 1997.

14. Oliver, P. Built to Meet Needs; Cultural Issues in Vernacular Architecture; Routledge: London, UK, 2006.

15. Rapoport, A. House Form and Culture; Prentice-Hall: Upper Saddle River, NJ, USA, 1969.

16. Xing, Q. Agricultural Tax to Be Scrapped from 2006. China Daily. 6 March 2005. Available online: http: //www.chinadaily.com.cn/english/doc/2005-03/06/content_422126.htm (accessed on 19 June 2016).

17. Chen, A. How has the abolition of agricultural taxes transformed village governance in China? Evidence from agricultural regions. China $Q$. 2014, 219, 715-735. [CrossRef]

18. Wang, X.; Shen, Y. The effect of China's agricultural tax abolition on rural families' incomes and production. China Econ. Rev. 2014, 29, 185-199. [CrossRef]

19. Watts, J. China Vows to Create a 'New Socialist Countryside' form Millions of Farmers. The Guardian. 22 February 2006. Available online: https://www.theguardian.com/world/2006/feb/22/china. jonathanwatts (accessed on 20 June 2016).

20. Ryan, C.; Huimin, G. Tourism in China: Destinations, Cultures and Communities; Routledge: London, UK, 2008.

21. Gao, Y.; Pitts, A.; Gao, J. The role of ecotourism in the sustainable development of Qinkou village, Yunnan, China, 2001 to 2013. In Proceedings of the International Association for the Study of Traditional Environments (IASTE), Kuala Lumpur, Malaysia, 14-17 December 2014; Volume 268, pp. 1-25. 
22. Gao, J. Faculty of Architecture and Urban Planning, Kunming University of Science and Technology, China. Personal communication, 2016.

23. In Kunming. Nuohei Village in Yunnan-A Village Built by Stones. Available online: http://en.kunming. cn/index/content/2014-12/31/content_3793975.htm (accessed on 23 June 2016).

24. Nuohei Yi Ethnic Group Cultural Museum, Visitor Information. 2016.

25. Chinese Union of Anthropological and Ethnological Sciences. The 16th International Union of Anthropological and Ethnological Sciences, handbook. Available online: http:/ / www.fti.uab.cat/interasia/ documents/guarne-16th\%20world\%20congress\%20iuaes\%202008.pdf (accessed on 25 August 2016).

26. Yunnan Tourism Information Network, Overnight at Slabstone House in Nuohei Village. Available online: http:/ / www.chinastoneforest.com/showArticle.aspx?cid=255\&aid=5231 (accessed on 23 June 216).

27. Marschalek, I. The concept of participatory local sustainability projects in seven Chinese villages. J. Environ. Manag. 2008, 87, 226-235. [CrossRef]

28. Pitts, A.; Gao, Y. Design of dwellings and interior family space in China: Understanding the history of change, and opportunities for improved sustainability practices. Buildings 2014, 4, 823-848. [CrossRef]

29. Pitts, A. Planning and Design Strategies for Sustainability and Profit; Architectural Press: Oxford, UK, 2004.

30. Jiang, W.; Pitts, A.; Gao, Y. Planning and design strategies for sustainable urban development. In Proceedings of the 1st International Conference on Sustainable Buildings and Structure, Suzhou, China, 30-31 October 2015.

31. Building Research Establishment. BREEAM Communities 2012. Available online: http:/ /www.breeam.com/ communities (accessed on 24 June 2016).

32. US Green Building Council. LEED v4 for Neighbourhood Development Plan. 2016. Available online: http:/ / www.usgbc.org/leed (accessed on 24 June 2016).

33. Chen, B.; Pitts, A.; Ward, I. Indicators for Sustainable Housing Design: From EcoHomes to the Code for Sustainable Homes. In Proceedings of the PLEA 2008, Dublin, Ireland, 22-24 October 2008.

34. Pitts, A. Future proof construction-Future building and systems design for energy and fuel flexibility. Energy Policy 2008, 36, 4539-4543. [CrossRef]

35. Wan, L.; Ng, E. Built environment sustainability assessment of poor rural areas of southwest China. In Proceedings of the 30th International PLEA Conference, Ahmedabad, India, 16-18 December 2014; Volume 1, pp. 386-393.

36. Liu, S.; Huang, C. Optimization of natural ventilation of "Yinzi" dwellings in western Hunan based on orthogonal experiment and CFD. Buildings 2016, 6, 25. [CrossRef]

37. Weissenstein, C.; Bignon, B.-C. Environmental design of a building: Climatic context. In Proceedings of the PLEA 2011 27th Conference on Passive and Low Energy Architecture, Louvain-la-Neuve, Belgium, 13-15 July 2011.

38. Baker, N.; Steemers, K. Energy and Environment in Architecture: A Technical Design Guide; Taylor and Francis: London, UK, 1999.

(C) 2016 by the author; licensee MDPI, Basel, Switzerland. This article is an open access article distributed under the terms and conditions of the Creative Commons Attribution (CC-BY) license (http://creativecommons.org/licenses/by/4.0/). 